\title{
José Batres Montúfar, Romántico Travieso, y sus Tradiciones de Guatemala
}

\begin{abstract}
T Eer las Tradiciones de Guatemala de Pepe Batres, después de haberse Lasomado al mundo de sus íntimas complejidades psíquicas, le permite al lector descubrir una serie de relaciones entre causa y efecto, que probablemente se le escaparían a quien desconociera las circunstancias en que al autor le tocó vivir. ${ }^{1}$ Cuando uno conoce esas circunstancias, se da cuenta del mecanismo de acción y reacción que funcionó entre Batres Montúfar y los que lo rodeaban, y comprende mejor el trasfondo de esas Tradiciones.
\end{abstract}

Todo parece indicar que operaban sobre Batres circunstancias de indole diversa que influían adversamente en su carácter y lo hacian proclive a la inadaptación social, a cierta forma peculiar de conducta que propiciaba el que muchos de sus coterráneos vieran en Batres un hombre completamente distinto del que en realidad él era. ${ }^{2}$ Es esto probablemente lo que hace que Adrián Recinos, en el estudio que acompaña a su edición de las obras del autor de las Tradiciones de Guatemala, nos lo presente como tímido ante las damas, poco afortunado en amores, extremadamente franco, de ideas independientes y avanzadas, mordaz en su crítica $y$, por consiguiente, "víctima de odios y prevenciones".

Sus características físicas no parecen haber sido las de Apolo, y aunque se discute el punto, y descontada la posible exageración del pintor guatemalteco que lo retrató, la longitud de su apéndice nasal no era de las que benefician estéticamente el rostro de un ser humano.3

I Sobre estas circunstancias y la compleja personalidad de Batres es interesante la lectura de la obra de José Arzú: Pepe Batres intimo (Guatemala, 1940).

2 Cf. Arzú, ob. cit., pp. 54-56.

3 Parece ser, según se ha dicho, que la prosopografía de don Cornelio que hace Batres en El relox ("...chico, gordo, colorado / ancho de las facciones y cuadrado") es su autorretrato. 
En lo afectivo no fue tampoco Pepe Batres de los más favorecidos, y hasta hubo en su vida un amor imposible."

Este hombre, además, tuvo que enfrentarse con una extremada pobreza, según se desprende fácilmente de la revisión de su correspondencia familiar, ${ }^{5}$ donde se relatan pormenores muy interesantes, entre ellos, la necesidad que tuvo el padre de Pepe, en cierta ocasión, de construirle a su hija Nela un par de zapatos con un forro de paraguas.

Junto a todo lo anterior, tuvo Batres la desgracia de su enfermedad y el dolor de la pérdida de su hermano Juan, dolor que se desborda en las dos últimas estrofas de su poema "Sañ Juan". ${ }^{6}$

Pepe Batres era, además, un hombre demasiado culto, demasiado exquisito para poder sobrevivir en un medio cultural, casi de aldea, que lo asfixiaba por completo. Tal vez por eso "la suya es una angustia de alma selecta y el spleen de que se queja y se acusa, a la vez, tiene sus raíces en el desencanto ... Pepe Batres era un incomprendido; asi se puede conjeturar por la misma índole de su obra, tan nueva y adelantada para su tiempo..." 7 "Sorprenderían, por tanto, su risa espontánea y la gracia fresca de su verso, si no fuese su vocación literaria un refugio contra la vida misma, su humorismo un antídoto de la amargura, su primor estilístico un trabajo aislante, su fantasía una evasión de la realidad y su predilección por las tradiciones la forma de eludir el ambiente de su época, y, en fin, su estudiada reticencia y su piadosa sátira, rebeldía latente y desahogada protesta". ${ }^{8}$

4 Según David Vela, Literatura Guatemalteca (Guatemala, 1944), p. 174, ese amor osciló entre Luisa Meany y Adela García Granados. Posiblemente se trata de la segunda de ellas. De la existencia de ese amor imposible dan muy buenas muestras el poema "Yo pienso en ti" $y$ una de las canciones que Batres compuso, una de cuyas estrofas dice:

Aquí en mi pecho oculta está

mi violenta pasión;

mudo a tu vista callará

temblando el corazón.

5 Véanse en José Arzú, ob. cit., el "Epistolario" y el capítulo "Pobreza de la familia".

6 Dicen esas dos estrofas:

Tu nombre tenía mi amigo, mi hermano. sobre él derramaste tu odioso veneno

apenas bebiendo su aliento lozano el hálito impuro que brota tu seno.

¡Por él te maldigo! ¿Por él te saludo!

Mis lágrimas guarda, maldito desierto;

de prados, de mieses, de flores desnudo, de fieras poblado, de selvas cubierto.

7 David Vela, ob. cit., p. 172.

8 Ibid.. n. 168. 
Basta revisar la correspondencia familiar de José Batres para darnos cuenta de su actitud frente a la vida: escéptico, resentido, burlándose de todo y de todos; pero capaz de llevar rizos de nieta en su portafolio. Basta también, para comprender todo esto, leer con cuidado su escasa producción no festiva: su "Yo pienso en ti", por ejemplo, donde nos habla de "la llama que en silencio" lo "devora", del "vano estrépito del mundo" y de cómo piensa en su amor imposible "sin lucha, sin afán y sin lamento", sin agitarse "en ciego frenesi, sin proferir un solo, un leve acento", o su "San Juan", donde describe el desierto primorosamente y, pensamos, lo iguala bastante con la sociedad en que se ve obligado a vivir y a la cual no puede adaptarse.

Todas las circunstancias apuntadas contribuyen a formar un Pepe Batres que en sus Tradiciones se burla, por reflejo, de la sociedad que lo asfixia, como un chico travieso se burla de la maestra que no lo comprende y lo castiga, colocándole en la silla una tachuela; no con el ánimo de herirla, sino para verla saltar al sentir el pinchazo, mientras él, oculio tras un texto de historia, parece no haber hecho nada y estar muy enfrascado en el estudio del pasado. Para nosotros las Tradiciones de Batres son sus travesuras literarias. En ellas usa su talento para tomar desquite, uno por uno, de todos los cornudos, de todos los hipócritas, de todas las mujeres que lo han despreciado, de todas las falsas virtuosas que van a misa por el día y engañan al marido por la noche, de todas las señoritingas que se ruborizan cuando oyen en público contar un chiste de verde muy pálido y se saben de memoria y los cuentan en privado, los mejores de la colección del verde más subido; en fin, de todos los estúpidos mediocres que lo rodean, y a los que es incapaz de sufrir. No pretende dañarlos, sólo desea colocarles la tachuela que los haga saltar, sólo quiere hacer de ellos títeres cómicos con los que pueda él jugar traviesamente, a su antojo, como juega un chico con sus monitos de juguete. $\mathrm{Y}$ ¡cómo lo logra! Es enorme su talento narrativo: de él dice Anderson Imbert:

...Su talento era primordialmente narrativo ... los mejores pasajes son esos en que el poeta llega a uno de los nudos de la intriga y allí nos suspende el ánimo con la curiosidad de saber qué va a ocurrir cuando los nudos se desaten ... Su imaginación imprime movimiento, vida, intenciones, gestos, aun a las cosas inanimadas. .."פ

Efectivamente, cualquiera de los tres de sus mejores relatos ( $E$ l relox, Don Pablo y Las falsas apariencias) es comparable, en el interés

9 Enrique Anderson Imbert, Histosia de la literatura bispanoamericana (México-B. Aires, ed, de 1962), t. I, p. 216. 
narrativo, a las Tradiciones de Palma; pero Batres, muy hábil en la versificación, especialmente en el manejo de la octava real, usa tal habilidad como una cerbatana con que disparar los dardos de sus burlas escondido en el pasado, con su libro de historia ocultándole el rostro. Sus travesuras consisten en eso, en clavarles desde lejos esos dardos a los que pretende ridiculizar. Con sus relatos, al alcance de todas las mentalidades (de ahí el haber llegado mejor que otros al pueblo), provoca la risa, no por dar directamente en el blanco, sino por las contorsiones cómicas que les hace hacer a los que hiere levemente de rechazo.

Los méritos de Batres no consisten, a nuestro juicio, en haber escrito versos más o menos buenos, ni en haber innovado un poco en sus octavas, ni en el uso que en ellas hace de consonantes raros, ni en el frecuente tránsito del endecasílabo común al anapéstico o de gaita gallega. La poesía, creemos, se envilece un tanto y hasta deja de ser poesía cuando se usa para ciertos menesteres, aunque el que lo haga sea un maestro en la versificación. Creemos, con Vela, que Las Tradiciones de Guatemala valen lo que valen por presentar reunidas otras muy diversas fuentes de la risa, lo cual ya nace de lo cómico del carácter, ya de los accesorios descriptivos y pintorescos, ya del contraste entre la entonación épica y de la llaneza prosaica, ya de la filosofia risueña y socartona, ya de la afectada y maliciosa ingenuidad, ya de la suspensión oportuna, y de la alusión picaresca..." 10

Batres, pese a lo que, según su propia confesión, tomó de Casti, 11 nunca nos hiere con obscenidades. Su gracia es fresca, simpática y, si cabe, hasta delicada; aunque quizá, para su época, un tanto licenciosa, a veces. $^{12}$

10 Ob. cit., p. 177.

Il Recinos, en sus notas, ha señalado estas influencias y las de Byron. También otros lo han hecho. Sin embargo, no tenemos noticias de que se haya reparado en un posible antecedente de "El relox". Nos referimos al segundo acto, escena novena (vs. 1600-1609) de La verdad sospecbosa, de Juan Ruiz de Alarcón, cuando don García le cuenta a su padre una mentira más en la que, por causa de un reloj que suena intempestivamente, se ve, como amante, envuelto en dificultades.

\$2 A este respecto, Vela (op. cit., p. 178) trae a colación un juicio de Menéndez y Pelayo que, por venir de quien viene, consideramos importante: "...Si hay caso en que pueda ser lícita, o a lo menos disculpable, la tolerancia ... uno de estos rarísimos casos" es, sin duda, el de Batres, con cuyos cuentos es imposible que deje de rérse a carcajadas el moralista más intransigente. $Y$ ot chiste no depende aquí de la vil lascivia, que nunca puede ser fuente de placer intelectual y desinteresado, sino de la virtud purificadora del donaire, y del prestigio elegantísima de la forma, la cual tiene por sí misma tal valor, que anula y destruye el prosaico y vulgar contento, y deja campear libre y sola la graciosa fantasía del poeta, a quien no se puede menos que admirar, lamentando al propio tiempo que malgaste tan opulenta vena cómica en tan vil materia..." En 1892, en. Santander, don Marcelino enjuició también muy favorablemente a Batres, consi- 
Batres, que según José Martí se reía y se moría a la vez, también cultivó lo serio. De su San Juan hay apreciaciones elogiosas muy dignas de ser tomadas en consideración. El propio Martí, al hablar de ese poema dijo, si no recordamos mal, que Batres había descrito el desierto con estrofas que quemaban y secaban. De modo que, si el travieso Batresi se lo hubiera propuesto, se habría destacado mucho en ese aspecto entre sus contemporáneos del romanticismo; peto aquí sólo concentraremos la atención en su producción jocosa, especialmente en las que consideramos sus tres mejores tradiciones: El relox, Las falstas apariencias y Don Pablo. Lo haremos de una manera general, tratando de destacar los recursos cómicos usados, y sin parar mientes en lo que haya de influencias de otros autores, lo cual ya Recinos ha realizado muy acertadamente en sus notas a la edición de las Tradiciones de Guatemala, hecha por el Departamento Editorial del Ministerio de Educación de El Salvador, en r96r. Todas las referencias aquî lo serán a esa edición.

La forma predominante en las Tradiciones es la octava real. Sólo excepcionalmente aparecen otras formas en sus cuentos, como en Suicidio, por ejemplo, donde se usa la décima, o en el cuento de la vieja solterona, en el que se mezclan heptasílabos con endecasílabos. Batres demuestra un buen dominio de la octava real como versificador, aunque hay hiatos tratados como sinalefas, lo cual resta fluidez al verso; se abusa bastante de la diástole y de la sístole, licencias que sólo muy excepcionalmente resultan gratas; y la precisión de la métrica se altera, en ocasiones, por cierta tendencia a renunciar a sinalefas y sinéresis. Por lo demás, sus octavas, pese al efecto no muy grato a nuestro oído que produce la mezcla del endecasílabo común con el de gaita gallega, que en ocasiones se hace, están bien tratadas y hasta presentan toques maestros de rima interna o leonina.

Pero lo importante en las Tradiciones no es el continente sino el contenido, con el cual se burla Batres de todo y de todos. De temas que contados en lenguaje no versificado serían relatos de poca extensión, chascarrillos comunes, saca el autor material extraordinatio para jugarles travesuras muy traviesas a los personajes y a su ambiente. Así, a las damas que nunca lo tomaron en consideración las ironiza con extremada gracia, las hace adoptar cómicas posturas y hasta a veces, sin usarlos, les aplica epítetos contundentes. En la primera parte de El relox, por ejemplo, dedica unas cuantas octavas a tomarles el pelo a las señoras, dando por descon-

derándolo "la verdadera gloria poética de Guatemala" y "cultivador de una poesía tan diversa, pero no menos exquisita en su género". (Véase Antología de poetas bisponoanerifanos, Madrid ${ }_{3} 1893$, t. I, p. CLXXII). 
tada la inutilidad de aconsejarlas, pero, al mismo tiempo, aconsejándoles la lectura de buenos libros y diciéndoles cosas como las de estos versos, cada uno de los cuales es una verdadera picada de tábano:

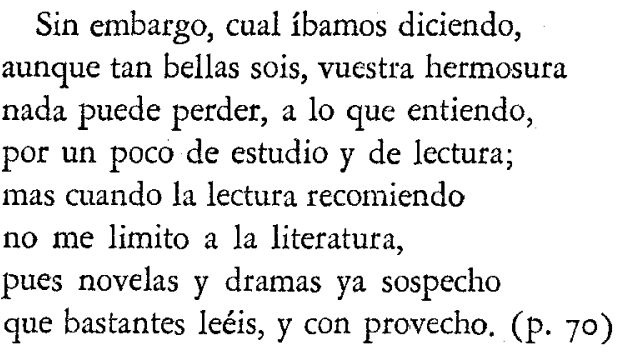

En la segunda parte de Don Pablo se vale de un recurso muy ingenioso para sugerir un duro epíteto aplicable a las mujeres cuya dimensión de castidad y virtud no aventaja a la de la dueña de la calavera. Nos referimos al uso de tres consonantes en "uta" que fuerzan una asociación inmediata con el epíteto en cuestión que, sin ser usado, queda claramente sugerido:

Aquel fragmento había sido parte de una bella mujer muy disoluta, que de Venus seguía el estandarte, de hombres haciendo amplísima recluta; pues de enganchar sabía a fondo el arte; érase el hueso de una rica fruta en cuya dulce pulpa en cien lugares habían caído moscas a millares. (p. 47)

Y a continuación, la ironía:

No son así mis jóvenes lectoras, que no pierden a nadie ni se envidian, ni lanzan miradillas seductoras, ni tienden redes, ni al amor convidan: antes bien, del decoro observadoras, de su beldad parece que se olvidan: que si el talle o el cuello nos descubren es por descuido y presto se lo cubren. (p. 47) 
Ciertas veces actúa a la manera de los reporteros gráficos cuando sorprenden a un personaje en actitud ridícula con una instantánea asesina de su cámara fotográfica, como en estas octavas de Don Pablo, en las que, además, usa el recurso de subrayar la palabra "futura", mediante Ia separación de sus letras, con una intención bien clara de destacar el valor semántico distinto al habitual que desea darle al vocablo:

Pablo en el coche se subió primero, y tomó de la mano a su futura, que apoyó en el estribo el pie ligero, y volvió la cabeza con presura antes de levantar el compañero, haciendo una bellisima figura, porque creyó escuchar algún ruido a modo de suspiro comprimido.

Suspensos ambos, Isabel y Pablo, en esta situación permanecieron como dos figurines de retablo, de cuya posición no se movieron, ni respiraron hasta ver qué diablo era aquel ruido que los dos oyeron. Quédense, pues, así por un momento, que necesito de tomar alimento. (pp. 34-35)

La respuesta de Isabel (quien no leía los billetes no por otra cosa que por no saber leer) al pajecito intermediario que nos hace recordar al Arcipestre, es una estocada a la virtud de aquellas damas:

... Ve y dile a don Pablito que es imposible hablarle..., que no puedo, porque a mamá le tengo mucho miedo. (p. 32)

Los militares salen de sus manos convertidos en verdaderos Tartarines, al personificarlos en el coronel de milicias retirado Diego de Mella:

Al fin eran las armas su ejercicio

y era famoso en ellas y temido, aunque ni en paz ni en guerra hizo el servicio mas se había mostrado decidido, 
impertérrito, audaz, sịn dar indicio

de temor, cuando hubo aquel ruido

de que pudiera ser que hubiese guerra

no sé si con la Francia o la Inglaterra.

(Don Pablio, pp. 30-3I)

Con gracia extraordinaria, manejando irónicamente los contrastes, se mofa de las costumbres imperantes, de la falsa moral, de la fingida sobriedad, de la pretendida abstinencia:

Entonces era todo muy distinto, todo era sobriedad, todo mesura; apenas se tomaba vino tinto, apenas se ostentaba la hermosura, apenas se salía del recinto de la estrecha, estrechísima clausura de la casa materna, y no a paseo, sino a misa mayor y al jubileo.

Si una niña tenía algún amante, o dos, o tres, o cuatro, o cinco, o ciento, era con un recato edificante, y no hablaba con ellos un momento si sus padres hallábanse delante; ni entraban ellos nunca en su aposento, pues si los recibía sólo era de noche, en el jardín o en la cochera.

Mas al presente ...

En la sala, en la calle, en el paseo, delante de diez mil espectadores con sus amantes a las damas veo tratar corrientemente sus amores

$$
\text { ................ (Ibid., pp. 26-27) }
$$

A veces, con un simple giro deja pasar la intención, como quien esquiva algo quitándose de en medio, para que ese algo alcance a quien está detrás. Tal ocurre, por ejemplo, cuando en Don Pablo dice sin decirlo que el joven encontró la puerta abierta a pleno propósito de la chica: 
pero, según mis cálculos, diré, no sabiendo en contrario cosa cierta, que es probable que entrara por la puerta. (p. 33)

Aprovecha cualquier ocasión para hacer saltar con su tachuela de chico travieso a quien se le antoja:

yo tengo que cumplir con lo of recido aunque en mi tierra lo contrario se usa. (p.37)

La intencionada ubicación de un adjetivo le permite jugar a capricho con la polisemia, como en este fragmento que tomamos de Don Pablo, donde el adjetivo "bendito" va antepuesto al sustantivo escapulario:

Fray José dejó al punto su breviario y encontró a don Pascual en el ingreso, quien le besó el bendito escapulario. (p. 43)

Con fina sorna lanza un concepto aparentemente ingenuo tras el que va escondido un mundo de mala intención, de malicioso equívoco. Así éste, bastante subidito de color y de propósito, en el que el fraile le dice al chico pecador que viene en busca de consejo:

Yo fui un gran pecador y gran malvado, $\mathrm{y}$ tu difunta madre, si viviera, te pudiera decir cuánto he pecado, que ella mejor que nadie lo supiera. (p. 46)

O éste, en el que refiriéndose a la joven que se había metido de monja, luego de su entrevista en el coche, dice:

Y la nombró portera la prelada porque la vio al zaguán aficionada. (p. 49)

O cuando en Las falsas apariencias propone suprimir las alcabalas para acabar con el contrabando, o cuando se burla finamente de los cornudos consentidores a través de sus octavas de la mencionada composición, o 
dice en su dedicatoria de $E l$ relox que considera su trabajo inédito porque "el estar impreso en un periódico de Guatemala es lo mismo que hallarşe en un archivo privado". (p. 67).

La falta de sindéresis de los integrantes de la sociedad queda al descubierto en las reacciones de la gente ante el "sonado" reloj de don Alejo, en sus comentarios al respecto, en la admiración estúpida que por don Alejo sienten, en la pintura hecha del engañado don Cornelio y en la ironía con que presenta a doña Clara, las reuniones en su casa las actitudes populares ante la caída de los caballeros, cuando las detonaciones espantan a los caballos.

Batres apela a infinidad de recursos para lograr la comicidad y derrama la gracia a manos llenas. Los personajes se mueven ágilmente, como si el autor fuera tirando de cuerdecillas invisibles para hacerlos mover. Con dos brochazos nos pinta una situación o un personaje. Tiene una noción cabal de lo ridículo y aprovecha a lo máximo tal noción para hacernos reír, como cuando en Las falsas apariencias nos dice que la señora del cuento era "una morenilla deliciosa" y a renglón seguido nos presenta al esposo deleitado en su contemplación, mientras interpreta como consecuencias del sueño profundo de la bella lo que en realidad no es más que el resultado sonoro de una infidelidad conyugal que ante los ojos del marido, ignorante de la presencia del mismo en la alcoba, estái cometiendo la esposa.

¿Cómo duerme, decía, cómo duerme mi hermosa, mi querida Mariquita!

¡Cuál demuestra su ardor para quererme, los suspiros que da, lo que se agita! (pp. 56-57)

Sus recursos son en ocasiones de teatro bufo, y hasta creemos que algunas situaciones podrían representarse sin palabras y moverían a la risa, como en esta octava de Las falsas apariencias:

Ardía en un rincón del aposento un angosto candil con débil llama del cual don Juan se apoderó violento y lo acercó a la orilla de la cama. Miráronse las caras un momento los suspensos tivales y la dama sin decirse palabra, como muertos, con los ojos extáticos y abiertos. (p. 48) 
O el duelo de los dos rivales "con tranca el uno, el otro con espada", o las escenas en la alcoba con don Alejo metido bajo la cama mientras el cornudo trata de lograr los favores de su propia esposa, quien lo rechaza una y otra vez y no se los otorga hasta que, al final, los da a cambio del dinero que el marido paga por el reloj de marras. ${ }^{13}$

En resumen, que José Batres Montúfar, el introvertido, el inadaptado, el hombre repudiado por las damas e incomprendido por sus coterráneos, el escritor pobre y de corazón destrozado por el dolor, enfermo de alma y de cuerpo, supo muy bien cobrar sus cuentas con la creación de sus Tradiciones de Guatemalia. Batres Montúfar fue un romántico travieso.

Duquesme University

ALBERTo ANDINo

13 El relox (segunda parte). Fue lo último que probablemente Batres escribió y quedó inconcluso. Hubo un autor que intentó una terminación, pero con poca fortuna. 
